Session TC1-3

\title{
Generation Generate: Digital Learning in the Classroom and Beyond
}

\author{
Michael Webber ${ }^{1}$, Kathy J. Schmidt ${ }^{2}$ and Juan Garcia ${ }^{3}$ \\ ${ }^{1}$ Assistant Professor, Mechanical Engineering, The University of Texas at Austin \\ ${ }^{2}$ Director, Faculty Innovation Center, The University of Texas at Austin \\ ${ }^{3}$ Video Producer, Faculty Innovation Center, The University of Texas at Austin
}

\begin{abstract}
Today's classrooms have many options for instructional delivery. In many classrooms, a blackboard has given way to whiteboards, document cameras, and data projectors. A smaller number of classes offer distance learning capabilities so that instruction is offered with an "any time, any place” mentality. Often times, however, instructional technology has been found to extend educational reach more than enhancing teaching and learning. When the emphasis is on access and the latest instructional technology tool, students are likely not getting much benefit from the plethora of new technologies. Yet these "digital natives" are primed to learn from and with technology. Their lives outside the classroom are rich with technological tools and many contend their learning preferences are adapting to a digital, multimedia rich approach. In one graduate level mechanical engineering energy class, the intention was to not only integrate instructional media into the curriculum, but to assess the impact of these tools. Lectures have been made interactive by the use of clickers, where the professor initiates a multiple choice question and students using remote devices key in their answers. Outside of the classroom, students respond to blogs and are able to create podcasts (an audio or video file distributed over the Internet to an appropriate media player or personal mobile device). Students were given pre- and post-surveys to ascertain time commitments, skills needed, level of enjoyment, and perceptions of their learning. We will provide a comparison of these results and provide usage statistics on the blogs as well as give suggestions for those considering integrating these technologies in a curriculum.
\end{abstract}

